\title{
NEOPHRASEOLOGIZATION IN BULGARIAN (IN COMPARISON WITH RUSSIAN)
}

\section{DiANA BLAgOEVA}

Institute For Bulgarian LANGUAGE, Bulgarian ACADEMY OF SCIENCES

d.blagoeva@ibl.bas.bg

The article deals with new phraseological units which came into existence in the Bulgarian language at the end of the $20^{\text {th }}$ and the beginning of the $21^{\text {st }}$ century. New phrasemes in Russian are considered as well for the purposes of comparison. The most active mechanism for the formation of new phraseological units in both languages is discussed. Attention is also paid to the sources for enriching the phraseological stock of the studied languages. The expansion of colloquial units and the penetration of phrasemes from the language of various social groups, the language of advertising and media discourse, the language of public figures and the language of subcultures have had a significant impact on the phraseological system. Another source of enrichment is the transfer (loan translation) of phraseological units from some West European languages, especially from English.

Keywords: phraseology, new phraseological units, Bulgarian language, Russian language

\section{REFERENCES}

Alefirenko 2008: Alefirenko, N. F. Frazeologija v svete sovremennykh lingvisticheskikh paradigm. Moskva, Elpis.

Alefirenko, Semenenko 2009: Alefirenko, N. F., N. N. Semenenko. Frazeologija i paremiologija. Moskva, Izdatel'stvo "Flinta", Izdatel'stvo "Nauka".

Armyanov 2011: Armyanov, G. Sotsialniyat opit v izgrazhdaneto i razvitieto na sotsiolektite. - In: Ezikat i sotsialniyat opit. Sofia, Mezhdunarodno sotsiolingvistichesko druzhestvo, s. 128-132.

Basko 2016: Basko, N. V. Frazeologicheskie neologizmy russkogo politicheskogo diskursa. - Politicheskaja lingvistika, 1(55), s. 58-65.

Basko 2018: Basko, N. V. Frazeologicheskie neologizmy v russkom jazyke: semantika, etimologija, funkcionirovanie. - Filologicheskie nauki. Voprosy teorii i praktiki, 3(81), s. 64-66.

Blagoeva, Kolkovska 2009: Blagoeva, D., S. Kolkovska. Semantichna prozodiya na nyakoi grupi kauzativni glagoli v balgarskiya ezik (korpusno bazirano izsledvane). - In: Bulharská a slovenská lexikografia v zjednotenej Európe. Bratislava, Slavistycký ústav Jána Stanislava SAV, Veliko Tarnovo, IK “Znak'94”, s. $58-72$. 
Blagoeva, Sosnowski, Kolkovska 2018: Blagoeva, D., V. Sosnowski, S. Kolkovska. Frazeologichni inovatsii v balgarskiya i polskiya ezik. - Balkanistichen forum, 3, s. 9-20.

Bondzholova 2015: Bondzholova, V. Osobenosti na reklamniya ezik i stil. Leksikalen aspekt. Veliko Tarnovo, Faber.

Butseva et al. 2009-2014: Butseva, T. N. et al. Novye slova i znachenija. Slovar'spravochnik po materialam pressy i literatury 90 -h gg. T. 1-3. Sankt-Peterburg, Dmitrij Bulanin.

Georgieva 2011: Georgieva, St. Za haraktera na frazeologichnite neologizmi v balgarskiya ezik. - In: Ezikovedski izsledvaniya v chest na prof. Siyka Spasova-Mihaylova. Sofia, Akademichno izdatelstvo "Prof. Marin Drinov", s. 163170 .

Georgieva, Velichkova 2008: Georgieva, St., S. Velichkova. Frazeologichnite neologizmi v balgarskiya ezik i tehnite saotvetstviya v drugi slavyanski ezitsi. - In: Slavyanska filologiya. T. 24. Sofia, Akademichno izdatelstvo "Prof. Marin Drinov", s. 286-299.

Gudkov 2003: Gudkov, D. B. Teorija i praktika mezhkul'turnoj kommunikatsii. Moskva, Gnozis.

Hadzhieva, Manova 2019: Hadzhieva, E., R. Manova. Novi frazeologizmi v balgarskata razgovorna praktika na chuzhdentsi. - In: Dokladi ot Mezhdunarodnata godishna konferentsiya na Instituta za balgarski ezik "Prof. Lyubomir Andreychin" (Sofia, 14-15 may 2019 godina). Sofia, Izd. na BAN "Prof. Marin Drinov", s. 83-90.

Kaldieva-Zaharieva 2013: Kaldieva-Zaharieva, St. Balgarska leksikologiya i frazeologiya. T. 2. Balgarska frazeologiya. Sofia, Akademichno izdatelstvo "Prof. Marin Drinov".

Karaulov 1987: Karaulov, Ju. N. Russkij jazyk i jazykovaja lichnost'. Moskva, Nauka.

Kiryakova-Dineva 2008: Kiryakova-Dineva, T. Za frazeologizatsiyata. Nyakoi novi modeli pri vaznikvaneto na novite frazeologizmi. - Ezikov svyat, 6, s. 52-56.

Kolkovska, Blagoeva 2017: Kolkovska, S., D. Blagoeva. Determinologizatsiyata i neynata rolya $\mathrm{v}$ neologizatsionnite protsesi $\mathrm{v}$ savremenniya balgarski ezik (v sapostavka s polski). - In: Balgarsko-polski studii. Sofia, Avangard Prima, s. 60-90.

Konstantinova 2008a: Konstantinova, D. Za nyakoi frazeologichni neologizmi v balgarskiya ezik. - In: Slavistichni prouchvaniya. Veliko Tarnovo, UI "Sv. sv. Kiril i Metodiy", s. 57-66.

Konstantinova 2008b: Konstantinova, D. Frazeologichni neologizmi v balgarskiya ezik, motivirani ot obshtestveno-politicheskiya zhivot sled promenite prez 1989 g. - In: Mokienko W., Walter, H. (eds.). Komparacja systemów i funkcjonowania współczesnych języków słowiańskich. 3. Frazeologia. Greifswald - Opole, Universität Greifswald, Institut für Slawistik, Uniwersytet Opolski, Instytut Filologii Polskiej, s. 297-304.

Konstantinova 2013: Konstantinova, D. Neologizmite i frazeologichnite neologizmi pri prepodavane na balgarski ezik kato chuzhd. - Opera Slavica, 4, s. 215-220.

Kunin 1980: Kunin, A. V. Frazeologicheskaja derivatsija v anglijskom jazyke. - In: Voprosy slovoobrazovanija i frazoobrazovanija v germanskikh jazykakh. Moskva, s. $155-162$. 
Kyuvlieva-Mishaykova 2005: Kyuvlieva-Mishaykova, V. Za nyakoi novi frazeologizmi v balgarskiya ezik v godinite na prehoda (1990-2005). - Slavica Slovaca, 2, s. $140-143$.

Kyuvlieva-Mishaykova 2008: Kyuvlieva-Mishaykova, V. Koruptsiyata, prestapnostta i politicheskite nravi vav frazeotvorchestvoto $\mathrm{v}$ balgarskiya ezik v posttotalitarnoto obshtestvo (1989-2006). - In: Mokienko W., H. Walter (red.). Komparacja systemów i funkcjonowania współczesnych języków słowiańskich. 3. Frazeologia. Greifswald - Opole, Universität Greifswald, Institut für Slawistik, Uniwersytet Opolski, Instytut Filologii Polskiej, s. 268-273.

Mokienko 2006: Mokienko, V. M. Leksicheskie i frazeologicheskie neologizmy: obshchee i razlichnoe. - In: Russkaja akademicheskaja neografija (k 40-letiju nauchnogo napravlenija). Sankt-Peterburg, Lema, s. 116-121.

Mokienko 2016: Mokienko, V. M. Russkie lihie devjanostye v leksikograficheskom zerkale. - In: Leksikografiyata v nachaloto na XXI v. Sofia, AI "Prof. Marin Drinov", s. 498-515.

Mokienko, Walter 2008: Mokienko W., H. Walter (eds.). Komparacja systemów i funkcjonowania współczesnych języków słowiańskich. 3. Frazeologia. Greifswald - Opole, Universität Greifswald, Institut für Slawistik, Uniwersytet Opolski, Instytut Filologii Polskiej.

Nahimova 2007: Nahimova, E. A. Pretsedentnye imena v massovoj kommunikatsii. Ekaterinburg, Ural'skij gosudarstvennyj pedagogicheskij universitet.

Nedkova 2015: Nedkova, E. Frazeogramaticheska harakteristika na frazeologichnite inovatsii v balgarskiya ezik. - In: Nauchnoe nasledie akademika V. I. Borkovskogo i sovremennaja russkaja slovesnost'. Materialy Mezhdunarodnoj nauchnoj konferencii. Volgograd, Volgogradskij gosudarstvennyj universitet, s. 304-311.

Nedkova 2017: Nedkova, E. Osnovni kontseptosferi na frazeologichnite inovatsii v balgarskiya ezik. - In: Arnaudov sbornik, t. 9. Ruse, LENI-AN, s. 429-432.

Nicheva 1987: Nicheva, K. Balgarska frazeologiya. Sofia, Nauka i izkustvo.

Nisheva 2018: Nisheva, B. Neografskoto predstavyane na frazeologichnite neologizmi v balgarskiya i v cheshkiya ezik. - In: Slovanská lexikografie počátkem 21. století. Praha, Slovanský ústav AV ČR, s. 347-354.

Parzulova 2015: Parzulova, M. Za ezikovata igra v balgarskite medii. - In: Lingvistikata: istoriya, predizvikatelstva, perspektivi. Blagoevgrad, UI "Neofit Rilski”, s. 291-297.

Pernishka, Blagoeva, Kolkovska 2001: Pernishka, E., D. Blagoeva, S. Kolkovska. Rechnik na novite dumi i znacheniya v balgarskiya ezik. Sofia, Nauka i izkustvo.

Pernishka, Blagoeva, Kolkovska 2010: Pernishka, E., D. Blagoeva, S. Kolkovska. Rechnik na novite dumi v balgarskiya ezik (ot kraya na XX i nachaloto na XXI vek). Sofia, Nauka i izkustvo.

Petrova 2010: Petrova, N. V. Jevoljucija ponjatija ,precedentnyj tekst“. - Vestnik Irkutskogo gosudarstvennogo lingvisticheskogo universiteta, s. 176-182.

Petrova, Denizov 2014: Petrova, R., B. Denizov. Za pretsedentnite tekstove i lingvokulturologiyata. - Nauchni trudove na Rusenskiya universitet, t. 53, seria 5.2, s. 204-210.

RBE 2001: Rechnik na balgarskiya ezik. T. 1 (A-B). 2. dop. i prerab. izd. Sofia, AI "Prof. Marin Drinov", ET "EMAS". 
RBE 2006: Rechnik na balgarskiya ezik. T. 3 (G-Deyatel). 2. dop. i prerab. izd. Sofia, AI "Prof. Marin Drinov", ET "EMAS".

Sknarev 2014: Sknarev, D. S. Neofrazeologizm kak sredstvo sozdanija obraza v reklamnom diskurse. Jelektronnyj nauchnyj zhurnal Sovremennye problemy nauki i obrazovanija, 4. $<$ https://www.science-education.ru/ru/article/view?id= 14127> (data na dost\#p: 23.01.2018).

Sosnowski, Blagoeva, Tymoshuk 2018: Sosnowski, W., D. Blagoeva, R. Tymoshuk. New Bulgarian, Polish, and Ukrainian phraseology and language corpora. Cognitive Studies/Études Cognitives, 18, pp. 1-14. < https://doi.org/10.11649/ cs.1768>.

Stepanova 2011: Stepanova, L. (red.) Slovar' novoj russkoj leksiki i frazeologii. Olomouc.

Val'ter 2008. Val'ter, H. Protsessy neologizatsii v sovremennoj russkoj i slavjanskoj frazeologii. - Przegląd Rusycystyczny, 4, s. 27-39.

$\triangle$ Prof. Diana Blagoeva, PhD

Department of Bulgarian Lexicology and Lexicography Institute for Bulgarian Language, Bulgarian Academy of Sciences 52 Shipchenski prohod, B1. 17, Sofia 1113, Bulgaria 